RUNNING HEAD: Practices and Opinions about Bilingual Services

\title{
Professional Practices and Opinions about Services Available to Bilingual Children with \\ Developmental Disabilities: An International Study
}

\author{
Stefka H. Marinova-Todd, Paola Colozzo, Pat Mirenda, and Hillary Stahl \\ University of British Columbia, Vancouver, BC Canada \\ Elizabeth Kay-Raining Bird and Karisa Parkington \\ Dalhousie University, Halifax, NS Canada \\ Kate Cain \\ Lancaster University, Lancaster, UK \\ Julia Scherba de Valenzuela \\ University of New Mexico, Albuquerque, NM USA \\ Eliane Segers \\ Radboud University, Nijmegen, Netherlands \\ Andrea A. N. MacLeod \\ Université de Montréal, Montreal, PQ Canada \\ Fred Genesee \\ McGill University, Montreal, PQ Canada
}

Accepted for publication in Journal of Communication Disorders, 9 May 2016

Corresponding author:

Stefka H. Marinova-Todd

School of Audiology and Speech Sciences

The University of British Columbia

2177 Wesbrook Mall

Vancouver, BC, Canada, V6T 1 Z3

Phone: 604 822-0276

E-mail: stefka@audiospeech.ubc.ca 
Keywords: bilingualism; developmental disabilities; preschoolers; school-aged children; service delivery

\begin{abstract}
This study aimed to gather information from school- and clinic-based professionals about their practices and opinions pertaining to the provision of bilingual supports to students with developmental disabilities. Using an online survey, data were collected in six socio-culturally and linguistically diverse locations across four countries: the United States, Canada, the United Kingdom, and the Netherlands. In total, 361 surveys were included in the analysis from respondents who were primarily teachers and speech-language pathologists working in schools, daycares/preschools, or community-based clinics. The overall picture that emerged from the data reflected a disconnection between practice and opinion. In general, respondents believed that children with both mild and severe disabilities are capable of learning a second language, although their opinions were more neutral for the latter group. However, children with both mild and severe disabilities who spoke only a minority language at home had less access to services for second language learners than did their typically developing peers, although respondents agreed that such services should be more available. Regardless of clinical group, children who lived in homes where a minority language was spoken were often exposed to, assessed in, and treated in the majority language only; again, respondents generally disagreed with these practices. Finally, second language classes were less available to children in the two disability groups compared to typically developing bilingual children, with general agreement that the opportunity to acquire a second language should be more available, especially to those with mild disabilities. Although the results indicate that there is a considerable gap between current practices and professional opinions, professionals appear to be more supportive of bilingual educational opportunities for these populations than was suggested by previous research.
\end{abstract}




\section{Professional Practices and Opinions about Services Available to Bilingual Children with Developmental Disabilities: An International Study}

\section{Introduction}

In an increasingly globalized society, bilingualism and multilingualism are topics of interest for many policy makers, educators, and child development specialists. Many children grow up in communities where bilingualism is a necessity, rather than a choice (de Houwer, 1999); they need two or more languages in order to participate in society and communicate with the important people in their lives. Even for children whose home language matches the majority language of the society, learning additional languages can provide economic and social benefits. However, for children with developmental disabilities, the need for bilingualism is not always perceived as a priority. Many parents of children with disabilities such as Down syndrome (DS), specific language impairment (SLI), and autism spectrum disorder (ASD) are advised by professionals -- including physicians, early childhood educators, and speech-language pathologists -- to raise their children monolingually (Kay-Raining Bird, Lamond, \& Holden, 2012; Kohnert, Yim, Nett, Kan, \& Duran, 2005; Thordardottir, 2002). In fact, the services these children require (e.g., specialized assessments or therapy programs) are often unavailable in minority languages, resulting in a systematic lack of access to individualized interventions (D’Souza, Kay-Raining Bird, \& Deacon, 2012). In addition, children with disabilities are often counselled away from participating in optional second language instruction in school (Genesee, 2007).

Until recently, there has been limited research on the effect of multiple language exposure on language development in special populations. The largest body of research in this area has been focused on monolingual and bilingual children with SLI, with research from many countries contributing to this effort. In a summary of this research, Paradis (2010) found that 
“simultaneous bilingualism does not necessarily exacerbate the language development of children with SLI” (p. 247) and that "most evidence to date leans toward a positive attitude toward dual language learning for children with SLI who are in a supportive context for bilingualism” (p. 248). In addition, a small but growing body of research has compared early language development in children with ASD who are raised in monolingual versus bilingual households. All of these studies reached the same conclusion across a wide range of language measures: exposure to a second (or even a third) language does not negatively affect early language development in children with ASD (Hambly \& Fombonne, 2012, 2014; Ohashi et al., 2012; Petersen, Marinova-Todd, \& Mirenda, 2012; Reetzke, Zou, Sheng, \& Katsos, 2015; Valicenti-McDermott et al., 2013). These results were echoed in three studies that employed various measures to compare aspects of early language development in monolingual and bilingual children with Down syndrome; in fact, in language samples, the bilingual children in these studies had larger lexicons and higher mean length of utterances (MLUs) than their monolingual counterparts (Feltmate \& Kay-Raining Bird, 2008; Kay-Raining Bird, Trudeau, Thordardottir, Sutton, \& Thorpe, 2005; Trudeau, Kay-Raining Bird, Sutton, \& Cleave, 2011).

Many of the studies reported previously were conducted in Canada, an officially bilingual country; thus, one might argue that the studies were conducted in a socio-cultural context that is especially supportive of bilingualism. However, some of the studies were also carried out in other countries, such as the United States (U.S.) (e.g., Valicenti-McDermott et al., 2013) and China (e.g., Reetzke, Zou, Sheng, \& Katsos, 2015), providing support to the notion that the findings were not a result of the specific socio-cultural context, but were more likely reflective of the participants' bilingual experience itself. Further support for this argument came from a study conducted in the U.S., which revealed that Spanish-English bilingual children with various degrees of bilingualism were not at an increased risk for language impairment, and that the 
overall language abilities of the bilingual and monolingual children were equivalent (Peña, Gillam, Bedore, \& Bohman, 2011).

From this research, it appears that bilingual language exposure, at least prior to school entry, is not likely to have a negative impact on language development. However, this conclusion is often not evident in the decisions made by parents and professionals who provide services and supports to children with developmental disabilities. For example, in an early study, Kremer-Sadlik (2005) interviewed four sets of bilingual parents who were told by professionals to speak only English at home after their child received an ASD diagnosis; the parents complied, to various degrees, with a number of deleterious effects on family socialization and cohesion (e.g., the parents were less likely to address their child with ASD, the child did not engage in family conversations, and the parents rarely used English in family conversations). More recently, Fernandez y Garcia, Breslau, Hansen, and Miller (2012) and Jegatheeson (2011) interviewed two groups of bilingual mothers whose children had ASD. These mothers were also advised by health care providers to speak only English and to avoid using their native languages when communicating with their children with ASD. They reported struggling with feelings of loss and deep sadness after making the switch, and also reported that this resulted in numerous social barriers within their family, community, and cultural settings. In contrast, Yu (2013) interviewed Chinese-English mothers who also changed their home language to English based on professional advice after an ASD diagnosis. Yu reported that many of them believed that a bilingual lifestyle was not the most ideal situation for their child and would negatively affect their children’s learning. Yu pointed out, however, that their beliefs were likely influenced by prior advice from child development professionals. Together, these studies reflect the survey data in a recent study by Kay-Raining Bird et al. (2012), in which 49 parents of children with ASD from six different countries were interviewed about their experiences of raising children with 
ASD in multilingual homes. Of the 28 parents who reported receiving advice about language exposure from professionals, $62.5 \%$ were consistently advised not to expose their child to more than one language, $25 \%$ received mixed advice, and only $12.5 \%$ of parents were encouraged to continue exposing their child to more than one language. However, $78 \%$ of the 49 parent participants reported that their children with ASD were able to learn more than one language with varying degrees of language comprehension, functional ability, and literacy across individuals. These studies highlight a clear disconnection between professional advice and parental beliefs regarding the importance of bilingual language development.

Research to date has been primarily focused on the effect of bilingualism on the child's functioning and well-being in the home environment. However, students with developmental and other disabilities also attend school and receive therapy in clinical settings; in fact, schools and clinics are the settings where most of their formal learning takes place beginning in the preschool years. Some research has documented the challenges faced by school-based speech-language pathologists who provide supports to linguistically-diverse students (D’Souza et al., 2012; Roseberry-McKibbin, Brice, \& O’Hanlon, 2005) and have later provided specific guidance regarding what constitutes "best practice" when working with children who are not proficient in the majority language of schooling (Pieretti \& Roseberry-McKibbin, 2015; Stow \& Dodd, 2003). The fundamental principle of "best practice” when working with language-minority children is to conduct language assessment and intervention in both (or all) languages that the children speak, whenever possible, and this principle has influenced service delivery in the U.S. (Pieretti \& Roseberry-McKibbin, 2015), Canada (Crago \& Westernoff, 1997) and the United Kingdom (UK) (Mennen \& Stansfield, 2006). In reality, bilingual services are often not feasible given the diversity of languages spoken by the bilingual children in a given clinical setting, and the scarcity of speech-language pathologists who speak the necessary languages to perform and 
interpret comprehensive assessments, and provide dual language intervention (Paradis, Schneider, \& Duncan, 2013). As a result, practice recommendations have also focused on alternative means of assessment (e.g., use of parent report to obtain information about the abilities of bilingual children in their home/other languages), strategies to support the maintenance and continued development of a child's home language (e.g., working with bilingual assistants or educators; providing support to family members), and providing informed and appropriate service in the majority language (Paradis, 2016; Pieretti \& Roseberry-McKibbin, 2015). From the policy review by Pesco et al. (in this issue) it is apparent that, across the different sites, children who are attending school in the majority language receive varied and limited support for their home language and sometimes for the language of schooling as well.

Despite the increased attention to this important issue, very little is known about the actual school- or clinic-based policies and practices that affect the extent to which bilingual students with developmental disabilities (a) are exposed to and/or have access to assessment or treatment in more than one language, and (b) have opportunities for optional second language instruction as part of the school curriculum. We also know almost nothing about the current opinions of educational professionals in this regard - for example, do they believe that students with developmental disabilities are capable of learning a second language, or that they should have access to optional second language classes? Furthermore, do their opinions on such matters differ depending on the type of student (e.g., those with mild vs. severe intellectual disabilities)? In asking these questions, it is important to consider the role of the cultural and linguistic context as well - for example, service delivery in an officially bilingual country such as Canada might be quite different from those in the U.K., where English is the only official language. Although, from previous research in the U.K. (Crutchley, 1999; Mennen \& Stansfield, 2006; Stow \& Dodd, 2003) we know that the main principles of "best practice” are the same and speech-language 
therapists there face the same challenges when working with bilingual clients as the speechlanguage pathologists generally do in North America.

The purpose of this study was to gather information from school- and clinic-based professionals about their practices and opinions pertaining to the provision of bilingual supports to students with developmental disabilities in six socio-culturally and linguistically diverse locations: Albuquerque, New Mexico (USA), Halifax, Nova Scotia (Canada), Manchester, England (United Kingdom), Montreal, Quebec (Canada), Vancouver, British Columbia (Canada), and the Netherlands. English is the official language in Albuquerque and Manchester, and Dutch is the official language of the Netherlands. Both English and French are official languages in Canada; however, of the three Canadian sites, Montreal is the only one where the majority language of instruction is French (see Pesco et al., this issue). Note that, in contrast to the other sites, where $71 \%-100 \%$ of respondents were from a specific city, the sample from the Netherlands represents a wide geographic region in that country, but mostly in the area around Nijmegen, a city in the southeastern part of the country. These sites were chosen to reflect a variety of sociolinguistic contexts and a broad range of research expertise on DD and/or bilingualism (see Introduction and Pesco et al., this issue). More detailed information regarding the sites' ethno-linguistic composition and prevalence of bilingualism can be found in Pesco et al. (this issue).

\section{Method}

\subsection{Survey Development}

A survey was developed collaboratively by research team members representing all six sites. The survey consisted of 36 main items that were organized into five sections: (a) Section 1: Respondent demographic information (10 items, multiple choice and yes/no formats); Section 2: Statements pertaining to English/Dutch language learners (i.e., sequential bilinguals; defined as 
children who speak one language at home that is not used by the larger community and who are learning English/Dutch as an additional language; 7 items, rated on a scale from 1-5); Section 3: Statements pertaining to simultaneous bilinguals (defined as children who learn two languages at home early in life, one of which is the community majority language; 5 items, rated on a scale from 1-5); Section 4: Statements pertaining to optional second language (L2) learners (defined as children whose family speaks only the community majority language at home, but who opted to learn a second language outside of the home; 7 items, rated on a scale from 1-5); and Section 5: Bilingualism and bilingual services (7 questions, mixed formats). For all of the items included in the present study, respondents were asked to respond with regard to five groups: (a) typically developing (TD) children, (b) children with mild autism or intellectual disability (ID); (c) children with a language or reading impairment (LRI) only; (d) children with severe autism or ID; and (e) children with any disability who used an augmentative or alternative form of expressive communication (e.g., AAC: picture board, gestures/signs, speech-generating device, etc.). The survey was first constructed as a template and was then adapted for each research site, as needed to reflect regional cultural demographics. For example, in New Mexico, the definition of English language learner included an example of a child whose home language was Spanish but who was learning English at school, whereas the same definition in Vancouver referred to a child whose home language was Chinese but who was learning English at school. Participants were asked to respond about children in general, but in relation to their work environment (i.e., either preschoolers or school-aged children).

\subsection{Participants}

Survey responses were included in the analysis if the respondent (a) consented to use of the data, (b) provided sufficient demographic information, and (c) responded to at least one item in any section, from Sections 2-5. In total, 361 surveys met these criteria, although many were 
incomplete. Table 1 summarizes the respondent demographic information for all surveys that were included in the data set.

$<$ Table 1 here $>$

As seen in Table 1, the majority of respondents across all sites were female between the ages of 30-49. Occupations varied widely, although speech-language pathologists/therapists and teachers predominated. Schools were the most common workplaces, followed by daycares/preschools or various types of community-based clinics. While the workplace language for the majority (at least 86\%) of respondents was English (or, in the Netherlands, Dutch or Dutch Sign Language), the proportion of those who spoke a second language at home regularly varied dramatically (from $19.7 \%$ in Halifax to $97.3 \%$ in Montreal). It is important to note that, in Montreal, surveys were distributed through sites in which the language of instruction was either English or French. However, only four surveys were returned from sites where the primary language was French, and we elected not to include them in the analyses because of the small number. Thus, the Montreal data in this study only represent practices or opinions of respondents where English is the primary language in the workplace.

\section{$2.3 \quad$ Procedure}

The survey template and site-specific adaptations were developed using Opinio survey software (http://www.objectplanet.com/opinio/) and were posted on a secure web server housed at Dalhousie University in Halifax, Nova Scotia (Canada). The surveys reported in this study were available in a single language in five of the sites: English for Albuquerque, Halifax, Manchester, and Vancouver; and Dutch for the Netherlands. Both English and French surveys were available in Montreal, as noted previously. Respondents from each geographic site were recruited through various professional agencies and organizations representing teachers, speechlanguage pathologists, psychologists, child care workers, early childhood specialists, school 
administrators, and other professionals. The organizations and agencies sent out mass emails to their members with information regarding the survey and how to participate in the study. Parents of children with developmental disabilities were not recruited, as the focus of the survey was on professionals’ experiences and opinions. Interested participants were directed to the Opinio website where they found a description of the research study, a description of the procedures used to ensure confidentiality, and a form on which they consented for their responses to be included in the study. If they consented, the survey was opened to them online. The survey was available to potential respondents at all sites for an average of 4 months (range $=3-6$ months) and could be completed only once by a given respondent.

\subsection{Data Analysis}

In this report, we focused our analysis on a subset of items in the original survey that asked about practices and opinions regarding the capacity of, and the opportunities provided to, English/Dutch language learners, simultaneous bilinguals, and optional L2 learners in respondents' work environments. Six main practice items and seven main opinion items were examined. One item of each type pertained to English/Dutch language learners only; two items of each type separately pertained to both English/Dutch language learners and simultaneous bilinguals (for a total of 8 items); one set of items pertained to optional L2 learners only; and one opinion item pertained to all three groups. Respondents were asked to rate all parts of each item on a scale of 1-5; optional responses of "do not know" and "not applicable” were also provided in the survey but were not included in the present analyses. Appendix A displays the survey items and Appendix B displays the response formats for the practice and opinion items across the five groups.

Although there were only 36 survey items (including those related to demographics), each of 20 practice and opinion items required five responses, as displayed in Appendix B, for a 
total of 100 responses (i.e., 20 x 5). The length of the total survey likely explains why many surveys were only partially completed, with the final section on optional L2 learners having the lowest response rate. Nonetheless, in order to make maximum use of the data, we included all responses and used the number of responses (rather than the number of participants) as the unit of analysis for each site.

\subsubsection{Preliminary Analyses}

A preliminary examination of mean responses pertaining to the five groups suggested that TD children were viewed differently than children in the other four groups. In addition, it appeared that data for the mild autism/ID and the LRI groups patterned together, as did data for the severe autism/ID and the AAC groups. In order to examine these patterns empirically, and following Norman (2010), we considered these data as ratio and converted them to numerical values. Responses were converted from 1 to 5 for always to never, respectively, for practice items; and from 1 to 5 for strongly agree to strongly disagree, respectively, for opinion items (see Appendix B). We conducted t-tests to compare groups in each of the six sites, for all survey items of interest. In only two cases (out of 76 comparisons) were there significant differences ( $p$ $<.05$ ) for the mild autism/ID and LRI group comparisons; they corresponded to mean differences in opinion of 0.4 or less regarding the capacity of these children to learn more than one language, but all of the mean responses were in the strongly agree to agree range for this item. Furthermore, effect sizes were generally small (mean Cohen’s $d=.11$; range .00-.59). There were no significant differences for any item or site for the severe autism/ID and AAC group comparisons. Again, effect sizes for the 76 comparisons were generally small (mean Cohen's $d=.11$; range $.00-.48$ ). Based on these analyses, a decision was made to reduce the number of groups from five to three by combining responses to create one "mild" group and one “severe” group, with responses for TD children still considered separately. All subsequent 
analyses were conducted by comparing responses across these three groups: TD children, children with mild disabilities, and children with severe disabilities.

Our preliminary examination also suggested that responses to statements pertaining to each of the two bilingual groups (English/Dutch language learners and simultaneous bilinguals) patterned together. Thus, we again conducted preliminary analyses using a series of $t$-tests for responses to all target survey items for the three groups (TD, mild disabilities, severe disabilities) in each of the six research sites. There were no significant differences ( $p s \geq .074)$ in the mean responses for the two bilingual groups for any of the parallel survey items (Practice items: 2 and 3; 4 and 5; Opinion items: 3 and 4; 5 and 6; see Appendix A), and effect sizes for the 66 comparisons were generally small (mean Cohen’s $d=.13$; range .01-.48). Thus, we combined responses pertaining to all of the survey items that had parallel statements for the two groups, henceforth referred to as the "obligatory bilinguals" group. Here, we use the word obligatory as a shorthand descriptor and as a counterpoint to optional to reflect that bilingualism is due to family circumstances, while recognizing that families who use the language of instruction or the minority language at home do so by choice, not out of obligation.

\subsubsection{Main Analyses}

For our main analyses, our goal was simply to describe the practices and opinions expressed by respondents, in a way that allowed for meaningful cross-group and cross-site comparisons. Given this, descriptive data were generated for participant demographics and survey items using SPSS, Version 22.0. Mean scores and standard deviations were calculated to two decimal places and rounded up as needed, for all items both within and across sites for each of the three groups. To aid interpretability, the mean scores were then translated into word ranges that corresponded to the main ratings in the survey (e.g., mean responses from 1.8 to 2.2 were translated as often for practice and agree for opinion), as displayed in Table 2. Note that low 
scores on practice items indicate greater application of a practice and low scores on opinion items indicate stronger agreement.

$<$ Table 2 here $>$

\section{Results}

\subsection{Capacity to Learn a Second Language}

The first question we considered pertained to respondents’ opinions about the capacity of students in each of the three groups to learn more than one language. Missing data (i.e., no response) represented less than 30\% of responses for all sites, except for Montreal and the Netherlands (41\%-43\%). Figure 1 summarizes the mean responses across all six sites.

$<$ Figure 1 here $>$

Based on the mean responses, there was generally strong agreement that TD children and those with mild disabilities are capable of learning more than one language (1.3-1.6) but somewhat less endorsement (agree) of this capability for those with severe disabilities (2.2).

Table 3 displays the response rate, mean response, mean score, and standard deviation for each site.

$<$ Table 3 here $>$

Based on the mean ratings, there was general agreement on this issue across sites. Respondents in all sites expressed strong agreement that TD children have the capacity to learn a second language. Respondents in all sites, except for Albuquerque, were more reserved in their endorsement of bilingual capacity for children with mild and severe disabilities, with the latter group receiving the lowest endorsement. However, none of the mean site scores were in the disagree or strongly disagree range for this item. 


\subsection{Services for English/Dutch Language Learners}

The next two items pertained to practices and opinions about the availability of English/Dutch language services for English/Dutch language learners only. For example, in many schools, students who have a native language other than the majority language receive remedial services that are designed to either teach them the majority language or improve their ability to understand, speak, read, and/or write it. There were no parallel survey items for simultaneous bilinguals, as these students are not eligible for remedial services in any of the sites, so these analyses applied to English/Dutch language learners only (i.e., sequential bilinguals). For the survey items pertaining to this issue, data were missing (i.e., no response was provided) for less than $10 \%$ of responses in all sites except the Netherlands (14\%).

Figure 2 summarizes the practice and opinion responses for all six sites combined, across each of the three groups. Based on the mean responses, it appears that TD children and those with mild disabilities sometimes receive English/Dutch language services (2.8-2.9), while those with severe disabilities sometimes/rarely receive these services (3.4). In general, respondents agreed that English/Dutch language services should be more available to English/Dutch language learners in all three groups (1.8-2.0).

$<$ Figure 2 here $>$

Table 4 displays the response rate, mean response, mean score, and standard deviation for each site.

$<$ Table 4 here $>$

Respondents across sites reported considerable variability with regard to the availability of English/Dutch language services, which were most often available to TD children and least often available to those with severe disabilities. However, there were considerable differences between 
practice and opinion in all six sites, with the average response agreeing that such services should be available to everyone, regardless of site.

\subsection{Language Exposure for Obligatory Bilinguals}

This set of survey items pertained to practices and opinions about children's exposure to English/Dutch only in the respondents’ workplaces. For these items, the English/Dutch language learners and simultaneous bilinguals were combined, as described in the Preliminary Analysis section, to form the "obligatory bilingual” group. Missing data for these items accounted for less than $15 \%$ of responses in all sites except for Montreal (22\%) and the Netherlands (25\%). Figure 3 summarizes the practice and opinion responses for all six sites combined, across each of the three groups.

\section{$<$ Figure 3 here $>$}

The mean responses suggest that single language exposure in English/Dutch often occurs (2.3), and respondents tended to be neutral or to disagree with this practice (3.5-3.6), regardless of group.

Table 5 displays the response rate, mean response, mean score, and standard deviation for each site.

\section{$<$ Table 5 here $>$}

There was a wide range of mean responses to the practice item related to exposure. As noted previously, in Montreal, despite the fact that all respondents were from workplaces where the language used most often was English, children in all three groups were exposed only to English never or sometimes. This is congruent with the findings of Pesco et al. and de Valenzuela et al. (this issue) who reported that English school boards in Montreal offer mostly bilingual or French immersion programs rather than programs taught solely in English. In contrast, those in the Netherlands were often/always exposed to Dutch only. In the other four sites, responses were in 
the range of often to sometimes, regardless of the group. Respondents from most sites were neutral about or disagreed with single language exposure, with no distinctions made between the three groups. The exceptions were in Montreal for TD children and in Albuquerque for all three groups of children, where there was stronger disagreement with single language exposure.

\subsection{Language of Assessment and Treatment for Obligatory Bilinguals}

The next set of items pertained to practices and opinions about the language of educational assessment and treatment in the respondents’ workplaces. Data were examined for obligatory bilinguals in all sites except the Netherlands, where no comparable responses were available for Dutch language learners due to differences in the survey questions. ${ }^{1}$ Missing data (i.e., no response was provided) accounted for no more than $15 \%$ of responses in all sites except for Montreal (22\%). Figure 4 summarizes the practice and opinion responses for five sites combined, across each of the three groups.

$<$ Figure 4 here $>$

From this Figure, it appears that single language assessment and treatment occurs often across all sites (2.1-2.2), and respondents were neutral about or disagreed with this practice (3.6).

Table 6 displays the response rate, mean response, mean score, and standard deviation for each site.

$<$ Table 6 here $>$

${ }^{1}$ There were two differences that led to exclusion of these items from the Nijmegen data set. First, the questions were worded with respect to assessment and treatment in the first language rather than in Dutch — the majority language of instruction. Second, the addition of branching questions allowing respondents to consider the situation for speakers of Friesian (a language of instruction available in the province of Friesland) proved problematic, and resulted in very few responses for the general questions. 
Three general groupings were found with regard to assessment and treatment practices: (a) in Vancouver and Manchester, children in all three groups were often assessed and treated in English only; (b) in Halifax, this was almost always the case; and (c) in Albuquerque and Montreal, English-only assessment and treatment varied between rarely and sometimes, with somewhat greater tendency toward this practice for the mild and severe clinical groups. Respondents’ opinions about these assessment and treatment practices were less variable, with the strongest, most consistent disagreement expressed by respondents from Albuquerque across all groups. Respondents from the other sites were either neutral about or disagreed with this practice, with little variability across clinical groups.

\subsection{Language Classes for Optional Second Language Learners}

The final set of survey items explored practices and opinions about children who speak only one language at home and participate in second language classes at school or another setting. We did not include items pertaining to students enrolled in full-time immersion programs where the majority of the curriculum was delivered in a second language, due to differences in opportunities for immersion across sites (see Pesco et al., this issue); rather, these items only pertain to students enrolled in a single second language class at school. Missing data (i.e., no response) represent less than 30\% of responses, except for Montreal (46\%) and the Netherlands (42\%).

Figure 5 displays the practice and opinion responses for all six sites combined, across each of the three groups.

$$
<\text { Figure } 5 \text { here }>
$$

Based on the mean responses, TD children often participate in second language classes (2.2), children with mild disabilities often/sometimes participate (2.6), and those with severe disabilities sometimes/rarely participate (3.4). Respondents agreed that the opportunity to learn 
a second language should be more available to TD children and those with mild disabilities (1.82.2), but expressed neutral agreement with this for individuals with severe disabilities (2.7).

Table 7 displays the response rate, mean response, mean score, and standard deviation for each site.

$<$ Table 7 here $>$

Current optional second language practices varied considerably; nonetheless, TD children and those with mild disabilities patterned together in all six sites, with classes ranging from always/often available (Manchester) to sometimes available (Albuquerque and Halifax) for both groups. In contrast, students with severe disabilities had less access to second language classes in all sites, ranging from often in Manchester to sometimes or rarely in Albuquerque, Halifax, and Vancouver. Opinions were less variable, with respondents in all sites agreeing that second language classes should be more available, especially for TD and mildly disabled students; again, there was less endorsement of this for students with severe disabilities, although no mean ratings were in the disagree or strongly disagree range for any group.

\section{Discussion}

This survey study examined current practices and professional opinions about bilingual opportunities and services available to students with developmental disabilities across six sites in four countries. We constructed the survey to assess practices and opinions that pertained to TD children and four clinical groups, and we anticipated that responses would differ for each of them. However, our preliminary analyses found that responses for the mild autism/ID and LRI groups patterned together, as did responses for the severe autism/ID and AAC groups. While the two "mild” groups share some obvious similarities (e.g., children in both groups struggle with language and reading skills), commonalities between the two "severe” groups are less obvious, at first glance. However, while many students who rely on AAC do not have severe intellectual 
disabilities, they often have significant motor and/or sensory impairments which, in combination with their speech deficits, make language acquisition especially challenging (e.g., students with cerebral palsy). Arguably, this is the common characteristic that resulted in similar responses for the severe autism/ID and AAC groups.

In general, respondents believed that children with both mild and severe disabilities are capable of learning a second language, although their opinions were more neutral about this for the children with severe disabilities. This reflects a good awareness of the current research on bilingual children generally (Peña et al., 2011), as well as those with diagnosed development delays, such as SLI (Paradis, 2010), ASD (Hambly \& Fombonne, 2012, 2014; Ohashi et al., 2012; Petersen et al., 2012; Reetzke et al., 2015; Valicenti-McDermott et al., 2013) and Down syndrome (Feltmate \& Kay-Raining Bird, 2008; Kay-Raining Bird et al., 2005; Trudeau et al., 2011). Despite this generally positive attitude, the overall picture that emerged from the data reflected a disconnection between opinion and practice and suggested that the needs of bilingual students with developmental disabilities are not adequately addressed. Children with both mild and severe disabilities who spoke only a minority language at home had less access to English/Dutch language services than did their TD peers, although respondents agreed that such services should be more available. Regardless of group, children who lived in homes where a minority language was spoken were often exposed to, assessed in, and treated in English (or Dutch) only; again, respondents generally disagreed with these practices. Finally, second language classes were less available to children in the two disability groups compared to TD children, with general agreement that the opportunity to learn a second language should be more available, especially to those with mild disabilities. All of these observations reflect that the respondents are generally aware of what are considered to be "best practices" when providing service delivery to bilingual children with developmental delays and disabilities, although 
implementation of these practices has not caught up with the recommendations made by researchers (Crutchley, 1999; Paradis, 2016; Pieretti \& Roseberry-McKibbin, 2015) and subsequently by the professional organizations of speech-language pathologists in Canada (Crago \& Westernoff, 1997), the UK (Mennen \& Stansfield, 2006), and the U.S. (ASHA, 2016). Clearly there are many barriers to overcome, some of which likely have to do with lack of resources generally, others that are specific to having the knowledge, skills, and resources for providing appropriate services to linguistically- and culturally-diverse groups of children. Practice recommendations that suggest alternatives when bilingual assessment and intervention it is not possible is one avenue to move forward from this apparent stalemate (e.g., Paradis, 2016; Pieretti \& Roseberry-McKibbin, 2015). Advocating for greater supports for both the home language and the language of instruction in school settings would be another. Although included in the original survey, space limitations prevented us from presenting data in this report about the specific barriers that limit the provision of bilingual services or the needs of respondents with respect to in-service education in this regard. More information regarding policies, service availability, and barriers and is available in Pesco et al., and de Valenzuela et al. (this issue).

Despite the discrepancies that were evident between practice and opinion, a number of positive findings also emerged from the data. The mean responses to opinion items about whether bilingual services should be more available to students with mild/severe disabilities were almost always in the strongly agree/agree range (scores of 1.0-2.2). Even the item about increased availability of second language classes, which received the least support across sites for the mild and severe clinical groups, was never scored in the disagree/strongly disagree range (i.e., scores of 3.3 or higher), suggesting that most respondents were open to this option. Overall, these results may not be representative of the views held by the majority of interventionists across the different sites. Due to the method of dissemination, the survey sample 
was not random. Respondents self-selected for participation; therefore, it is possible that those who chose to participate may have been particularly interested in this topic, or particularly up-todate on the research. However, it is still important to note the trends, which give a fairly clear, consistent message.

There were a number of differences across sites that are likely reflective of both the respondents themselves and the cultural-linguistic context in which they lived. For example, in Albuquerque, where a large proportion (44.4\%) of respondents spoke a second language and where bilingual services are highly defined and overseen by policy (see Pesco et al., this issue), opinions in support of increased bilingual services and availability were among the strongest, regardless of group. In Montreal, there was often a closer match between practice and opinion than in the other sites, probably because this is a predominantly bilingual city where the vast majority of both survey respondents (91.3\%) and the population in general learn to speak both French and English and do so regularly. In Manchester, where 93.3\% of respondents were from schools (Table 1), the high level of access to second language teaching (Table 7) likely reflects the structure of the National Curriculum, which includes a foreign language teaching strand that is compulsory for all students, including those with developmental disabilities. Finally, in Halifax, English-only exposure, assessment, and treatment was most common, perhaps because Halifax has the smallest bilingual population overall, compared to the other sites (Pesco et al., this issue). Nonetheless, despite these differences, there was considerable agreement on both practice and opinion responses across sites, suggesting that, at present, access to bilingual services and supports is less than adequate for students with developmental disabilities internationally. 


\subsection{Limitations and Future Research}

The primary limitations of this study were the small sample size and the fact that many questions were answered by only a subset of respondents, as can be seen from the response rates reported in Tables 3-7. As noted previously, this was most likely a side effect of the overall length and complexity of the survey, which required five responses to each of 20 main items. In addition, a considerable proportion of responses were in the “don’t know” or "not applicable” categories. Future research on this topic might endeavour to address this issue by, for example, focusing on only a single bilingual group (e.g., sequential or optional bilinguals) or by limiting the response requirements to fewer groups (e.g., TD, mild, and severe disabilities), as per our preliminary analyses. Another limitation is that all of the respondents from Montreal were from workplaces where English was the language used most often; thus, the practices and opinions of professionals working in French-speaking contexts—which would represent the majority—are not represented in this report, and should be addressed in future research. In addition, the wording of the surveys themselves varied somewhat in order to accommodate the cultural and linguistic contexts of six different sites; this might have resulted in discrepancies that affected interpretation of items as well as the associated responses. Of course, selecting more homogeneous sites could address this issue in future studies, but the result will also be that the breadth of practices and opinions represented in the results will be decreased, which will further limit the intercultural perspective that is the essence of our research program.

\subsection{Conclusion}

Previous studies examining bilingual practices for individuals with developmental and learning disabilities have focused primarily on parents’ experiences and opinions (e.g., Jegatheesan, 2011; Kay-Raining Bird et al., 2012; Yu, 2012). The results of these studies suggest that professionals often discourage parents from speaking more than one language at 
home and are generally not supportive of second language/bilingual educational experiences. Few studies have examined the perspectives of professionals who work with linguistically diverse clients in schools (e.g., D’Souza et al., 2012; Mennen \& Stansfield, 2006; RoseberryMcKibbin et al., 2005) and this is the first study to explore these issues cross-nationally with a specific focus on students with mild to severe developmental disabilities. This ambitious project sought to examine both the practices and opinions of a wide range of professionals in six locations across four different countries with widely diverse linguistic practices in places. Although the results indicate that there is a considerable gap between current practices and professional opinions, professionals appear to be more supportive of bilingual educational opportunities for this population than was suggested by previous research. 


\section{Acknowledgements}

Partial results from this study were presented as part of two seminars on bilingualism and children with special needs at the American Speech-Language Hearing Association Conventions in Orlando, FL, November 2014, and in Denver, CO, November 2015. Funding for the study was provided by a Partnership Development Grant (\#890-2011-0150) from the Social Sciences and Humanities Research Council of Canada. We thank all the survey respondents for taking the time to patiently provide their insight, thus assisting us in our research. 


\section{References}

American Speech-Language-Hearing Association. Bilingual Service Delivery. http://www.asha.org/PRPSpecificTopic.aspx?folderid=8589935225\&section=Key_Issues Accessed 29.03.16.

Crago, M., \& Westernoff, F. (1997). CASLPA - Position paper on Speech-Language Pathology and Audiology in the multicultural, multilingual context. Journal of Speech-Language Pathology and Audiology, 21, 223-224.

Crutchley, A. (1999). Bilingual children with SLI attending language units: getting the bigger picture. Child Language Teaching and Therapy, 15, 201-217. doi: $10.1177 / 026565909901500302$

de Houwer, A. (1999). Two or more languages: Some general points and practical recommendations. ERIC Digest (EDO-FL-99-03) (Washington, DC: US Department of Education, Office of Educational Research and Improvement, National Library of Education, under Contract No. ED-99-CO-0008).

De Valenzuela, J., Kay-Raining Bird, E., Parkington, K., Mirenda, P., Cain, K., MacLeod, A., \& Segers, E. (this issue). Access to opportunities for bilingualism for individuals with developmental disabilities: Key informant interviews. Manuscript submitted as part of the special issue at the Journal of Communication Disorders.

D’Souza, R., Kay-Raining Bird, E. \& Deacon, H. (2012). Survey of Canadian speech-language pathologists service delivery to linguistically diverse clients. Canadian Journal of Speech-Language Pathology and Audiology, 36, 18-39.

Feltmate, K., \& Kay-Raining Bird, E. (2008). Language learning in four bilingual children with Down syndrome: A detailed analysis of vocabulary and morphosyntax. Canadian Journal of Speech-Language Pathology and Audiology, 32, 6-20. 
Fernandez y Garcia, E., Breslau, J., Hansen, R., \& Miller, E. (2012). Unintended consequences: An ethnographic narrative case series exploring language recommendations for bilingual families of children with autism spectrum disorders. Journal of Medical SpeechLanguage Pathology, 20(2), 10-16.

Genesee, F. (2007). French immersion and at-risk students: A review of research findings. Canadian Modern Language Review, 63, 655-688. doi: 10.3138/cmlr.63.5.655

Hambly, C. \& Fombonne, E. (2014). Factors influencing bilingual expressive vocabulary size in children with autism spectrum disorders. Research in Autism Spectrum Disorders, 8(9), 1078-1089. doi: 10.1016/j.rasd.2014.05.013

Hambly, C., \& Fombonne, E. (2012). The impact of bilingual environments on language development in children with autism spectrum disorders. Journal of Autism and Developmental Disorders, 42(7), 1342-1352. doi: 10.1007/s10803-011-1365-z

Jegatheesan, B. (2011). Multilingual development in children with autism: Perspectives of South Asian Muslim immigrant parents on raising a child with a communicative disorder in multilingual contexts. Bilingual Research Journal, 34, 185-200. doi: $10.1080 / 15235882.2011 .597824$

Kay-Raining Bird, E., Lamond, E., \& Holden, J. (2012). Survey of bilingualism in autism spectrum disorders. International Journal of Language \& Communication Disorders, 47(1), 52-64. doi: 10.1111/j.1460-6984.2011.00071.x

Kay-Raining Bird, E., Trudeau, N., Thordardottir, E., Sutton, A., \& Thorpe, A. (2005). The language abilities of bilingual children with Down syndrome. American Journal of Speech-Language Pathology, 14, 187-199. doi: 10.1044/1058-0360(2005/019) 
Kohnert, K., Yim, D., Nett, K., Kan, P. F., \& Duran, L. (2005). Intervention with linguistically diverse preschool children: A focus on developing home language(s). Language, Speech and Hearing Services in Schools, 36, 251-263. doi: 10.1044/0161-1461(2005/025)

Kremer-Sadlik, T. (2005). To be or not to be bilingual: Autistic children from multilingual families. In J. Cohen, K. T. McAlister, K. Rolstad, \& J. MacSwan (Eds.), Proceedings of the 4th International Symposium on Bilingualism (pp. 1225-1234). Somerville, MA: Cascadilla Press.

Mennen, I., \& Stansfield, J. (2006). Speech and language therapy service delivery for bilingual children: a survey of three cities in Great Britain. International Journal of Communication Disorders, 41, 635-652. doi: 10.1080/13682820600623911

Norman, G. (2010). Likert scales, levels of measurement and the "laws" of statistics. Advances in Health Sciences Education, 15, 625-632. doi: 10.1007/s10459-010-9222-y

Ohashi, J. K., Mirenda, P., Marinova-Todd, S., Hambly, C., Fombonne, E., Szatmari, P., et al. (2012). Comparing early language development in monolingual- and bilingual- exposed young children with autism spectrum disorders. Research in Autism Spectrum Disorders, 6(2), 890-897. doi: 10.1016/j.rasd.2011.12.002

Paradis, J. (2010). The interface between bilingual development and specific language impairment. Applied Psycholinguistics, 31(02), 227-252. doi:

$10.1017 / \mathrm{S} 0142716409990373$

Paradis, J., Schneider, P., \& Duncan, T. S. (2013). Discriminating children with language impairment among English-language learners from diverse first-language backgrounds. Journal of Speech, Language, and Hearing Research, 56, 971-981. doi: 10.1044/10924388(2012/12-0050) 
Paradis, J. (2016). The development of English as a second language with and without specific language impairment: Clinical implications. Journal of Speech, Language, and Hearing Research, 59, 171-182. doi: 10.1044/2015_JSLHR-L-15-0008

Peña, E., Gillam, R., Bedore, L., Bohman, T. (2011). Risk for poor performance on a language screening measure for bilingual preschoolers and kindergarteners. American Journal of Speech-Language Pathology, 20, 302-314. doi: 10.1044/1058-0360(2011/10-0020)

Pesco, D., MacLeod, A., Kay-Raining Bird, E., Cleave, P., Trudeau, N., de Valenzuela, J., Cain, K., Marinova-Todd, S., Colozzo, P., Stahl, H., Segers, E., Verhoeven, L. (this issue). A multi-site review of policies affecting opportunities for children with developmental disabilities to become bilingual. Manuscript submitted for review as part of the special issue at the Journal of Communication Disorders.

Petersen, J. M., Marinova-Todd, S., \& Mirenda, P. (2012). Brief report: An exploratory study of lexical skills in bilingual children with autism spectrum disorder. Journal of Autism and Developmental Disorders, 42(7), 1499-1503. doi: 10.1007/s10803-011-1366-y

Pieretti, R., \& Roseberry-McKibbin, C. (2016). Assessment and intervention for English Language Learners with primary language impairment: Research-based best practices. Communication Disorders Quarterly,37, 117-128. doi: 10.1177/1525740114566652

Reetzke, R., Zou, X., Sheng, L., \& Katsos, N. (2015). Communicative development in bilingually exposed Chinese children with autism spectrum disorders. Journal of Speech, Language, and Hearing Research, 58(3), 813-825. doi: 10.1044/2015_JSLHR-L-13-0258 Roseberry-McKibbin, C., Brice, A., \& O’Hanlon, L. (2005). Serving English language learners in public school settings: A national survey. Language, Speech, and Hearing Services in Schools, 36, 48-61. doi: 10.1044/0161-1461(2005/005) 
Stow, C., \& Dodd, B. (2003). Providing an equitable service to bilingual children in the UK: A review. International Journal of Communication Disorders, 38, 351-377. doi: $10.1080 / 1368282031000156888$

Thordardottir, E. (2002, November). Parents' views on language impairment and bilingualism. Poster presented at the American Speech-Language-Hearing Association convention, Atlanta, GA.

Trudeau, N., Kay-Raining Bird, E., Sutton, A., \& Cleave, P. (2011). Développement lexical chez les enfants bilingues ayant le syndrome de Down. Enfance, 2011(3), 383-404. doi: 10.4074/s0013754511003089.

Valicenti-McDermott, M., Tarshis, N., Schouls, M., Galdston, M., Hottinger, K., Seijo, R.,...Shinnar, S. (2013). Language differences between monolingual English and bilingual English-Spanish young children with autism spectrum disorders. Journal of Child Neurology, 28(7), 945-948. doi: 10.1177/0883073812453204

$\mathrm{Yu}$, B. (2013). Issues in bilingualism and heritage language maintenance: Perspectives of minority-language mothers of children with autism spectrum disorders. American Journal of Speech-Language Pathology, 22(1), 10-24. doi: 10.1044/1058-0360(2012/10-0078) 
Table 1

Respondent Demographic Information (\%)

\begin{tabular}{|c|c|c|c|c|c|c|}
\hline \multirow[b]{2}{*}{ Demographic Variable } & \multicolumn{6}{|c|}{ Site } \\
\hline & $\begin{array}{c}\text { Albuquerque } \\
\quad(n=36)\end{array}$ & $\begin{array}{l}\text { Halifax } \\
(n=61)\end{array}$ & $\begin{array}{c}\text { Manchester } \\
(n=45)\end{array}$ & $\begin{array}{c}\text { Montreal } \\
(n=23)\end{array}$ & $\begin{array}{c}\text { Netherlands } \\
\quad(n=77)\end{array}$ & $\begin{array}{c}\text { Vancouver } \\
(n=119)\end{array}$ \\
\hline \multicolumn{7}{|l|}{ Gender } \\
\hline Male & 5.6 & 6.6 & 15.6 & 13.0 & 9.1 & 7.6 \\
\hline Female & 94.4 & 93.4 & 84.4 & 87.0 & 90.9 & 92.4 \\
\hline \multicolumn{7}{|l|}{ Age } \\
\hline$<30$ years & 11.1 & 4.9 & 20.0 & 34.8 & 22.1 & 11.8 \\
\hline 30-49 years & 69.4 & 63.9 & 55.6 & 56.5 & 57.1 & 52.9 \\
\hline$\geq 50$ years & 19.5 & 31.2 & 24.4 & 8.7 & 20.8 & 35.3 \\
\hline \multicolumn{7}{|l|}{ Occupation } \\
\hline Speech-language pathologist/therapist & 30.6 & 21.3 & 4.4 & 13.0 & 40.3 & 35.3 \\
\hline General or special education teacher & 16.7 & 27.9 & 46.7 & 4.3 & 16.8 & 23.6 \\
\hline \multicolumn{7}{|l|}{ Alternative/second language/language } \\
\hline immersion specialist* & 11.1 & 0 & 8.9 & 4.3 & 1.3 & 5.9 \\
\hline Early childhood educator/specialist & 11.2 & 21.3 & 2.2 & 13.0 & 1.3 & 3.4 \\
\hline Administrator/director/principal & 0 & 16.4 & 11.1 & 13.0 & 5.2 & 3.4 \\
\hline Other** & 30.6 & 13.1 & 26.7 & 43.5 & 33.8 & 27.7 \\
\hline
\end{tabular}

Table Continues 


\section{Workplace (could choose more than one)}

Daycare/preschool/early intervention center

33.2

39.3

2.2

34.8

2.6

10.0

School

66.7

39.3

93.3

60.9

53.2

63.0

Community-based center/clinic

13.9

29.5

4.4

26.1

46.8

37.0

Other

11.1

0

2.6

5.9

\section{Language use}

Workplace: English/Dutch (Netherlands) only

86.1

96.7

97.8

100

90.9

87.4

Home: Use two or more languages regularly

44.4

19.7

26.7

91.3

36.4

29.4

(most common second language is indicated)

(Spanish)

(French)

(mixed)

(French)

(English;

(French)

Dutch Sign

Language)

*This category includes individuals who identified themselves as English Language Learner specialists, English as a Second Language teachers, bilingual educators, and teachers in second language immersion programs.

**This category includes individuals who identified themselves as educational aides/assistants, occupational or physiotherapists, psychologists, diagnosticians, behaviour analysts, educational consultants, researchers/professors, linguists, and school counsellors. There were also a few cases in which occupation was not provided (Montreal, $n=2$; Netherlands, $n=1$; Vancouver, $n=1$ ). 
Table 2

Scales used to interpret the mean responses

\begin{tabular}{|c|c|c|c|c|c|c|c|c|}
\hline \multicolumn{9}{|c|}{ Practice Items } \\
\hline always & always/often & often & often/sometimes & sometimes & sometimes/rarely & rarely & rarely/never & never \\
\hline $1.0-1.2$ & $1.3-1.7$ & $1.8-2.2$ & $2.3-2.7$ & $2.8-3.2$ & $3.3-3.7$ & $3.8-4.2$ & $4.3-4.7$ & $4.8-5.0$ \\
\hline agree+ & agree+/agree & agree & agree/neutral & neutral & neutral/disagree & disagree & $\begin{array}{l}\text { disagree/ } \\
\text { disagree+ }\end{array}$ & disagree+ \\
\hline \multicolumn{9}{|c|}{ Opinion Items } \\
\hline
\end{tabular}


Table 3

Responses to whether children have the capacity to learn more than one language, by site

\begin{tabular}{|c|c|c|c|}
\hline & TD & Mild & Severe \\
\hline \multicolumn{4}{|c|}{ Albuquerque $(n=36)$} \\
\hline Response rate* & $69 \%$ & $68 \%$ & $58 \%$ \\
\hline Mean response & agree+/agree & agree+/agree & agree+/agree \\
\hline Mean (SD) & $1.3(0.5)$ & $1.5(0.5)$ & $1.6(0.7)$ \\
\hline \multicolumn{4}{|c|}{ Halifax $(n=61)$} \\
\hline Response rate & $75 \%$ & $70 \%$ & $66 \%$ \\
\hline Mean response & agree+ & agree+/agree & agree \\
\hline Mean (SD) & $1.2(0.4)$ & $1.6(0.8)$ & $2.0(1.1)$ \\
\hline \multicolumn{4}{|c|}{ Manchester $(n=45)$} \\
\hline Response rate & $80 \%$ & $77 \%$ & $63 \%$ \\
\hline Mean response & agree+ & agree+/agree & agree \\
\hline Mean (SD) & $1.1(0.3)$ & $1.5(0.8)$ & $1.9(1.0)$ \\
\hline \multicolumn{4}{|c|}{ Montreal $(n=23)$} \\
\hline Response rate & $57 \%$ & $54 \%$ & $54 \%$ \\
\hline Mean response & agree+ & agree+/agree & agree \\
\hline Mean (SD) & $1.0(0.0)$ & $1.5(0.8)$ & $2.2(1.5)$ \\
\hline \multicolumn{4}{|c|}{ Netherlands $(n=77)$} \\
\hline Response rate & $52 \%$ & $56 \%$ & $45 \%$ \\
\hline Mean response & agree+/agree & agree & neutral \\
\hline Mean (SD) & $1.7(0.9)$ & $2.0(0.8)$ & $2.9(1.2)$ \\
\hline \multicolumn{4}{|c|}{ Vancouver $(n=119)$} \\
\hline Response rate & $76 \%$ & $73 \%$ & $63 \%$ \\
\hline Mean response & agree+ & agree+/agree & agree/neutral \\
\hline Mean (SD) & $1.2(0.4)$ & $1.5(0.7)$ & $2.3(1.1)$ \\
\hline
\end{tabular}

Note. 1 = strongly agree (agree+), 2 = agree, 3 = neutral, 4 = disagree, 5 = strongly disagree.

*This is the percentage of respondents from a site who provided ratings of 1-5; “do not know/not applicable” responses were not included. 
Table 4

Responses to whether English (or Dutch) language learners do and should receive English/Dutch language learner services, by site

\begin{tabular}{|c|c|c|c|c|c|c|}
\hline & \multicolumn{3}{|c|}{ DO receive services? } & \multicolumn{3}{|c|}{ SHOULD receive services? } \\
\hline & TD & Mild & Severe & $\mathrm{TD}$ & Mild & Severe \\
\hline \multicolumn{7}{|c|}{ Albuquerque $(n=36)$} \\
\hline Response rate* & $75 \%$ & $69 \%$ & $65 \%$ & $78 \%$ & $83 \%$ & $78 \%$ \\
\hline Mean response & often/sometimes & sometimes & sometimes/rarely & agree+/agree & agree+/agree & agree+/agree \\
\hline Mean (SD) & $2.4(1.4)$ & $2.9(1.4)$ & $3.5(1.5)$ & $1.7(0.9)$ & $1.6(0.6)$ & $1.7(0.8)$ \\
\hline \multicolumn{7}{|c|}{ Halifax $(n=61)$} \\
\hline Response rate & $67 \%$ & $59 \%$ & $56 \%$ & $75 \%$ & $76 \%$ & $73 \%$ \\
\hline Mean response & sometimes/rarely & rarely & rarely & agree & agree & agree \\
\hline Mean (SD) & $3.5(1.4)$ & $3.9(1.2)$ & $4.1(1.1)$ & $1.9(1.2)$ & $1.9(1.1)$ & $2.0(1.1)$ \\
\hline \multicolumn{7}{|c|}{ Manchester $(n=45)$} \\
\hline Response rate & $76 \%$ & $71 \%$ & $57 \%$ & $87 \%$ & $87 \%$ & $80 \%$ \\
\hline Mean response & sometimes & sometimes & sometimes & agree & agree+/agree & agree \\
\hline Mean (SD) & $3.2(1.4)$ & $2.9(1.4)$ & $3.2(1.3)$ & $1.8(1.1)$ & $1.7(1.0)$ & $1.8(1.0)$ \\
\hline
\end{tabular}

Table Continues 


\begin{tabular}{|c|c|c|c|c|c|c|}
\hline \multicolumn{7}{|c|}{ Montreal $(n=23)$} \\
\hline Response rate & $35 \%$ & $37 \%$ & $41 \%$ & $39 \%$ & $54 \%$ & $54 \%$ \\
\hline Mean response & sometimes/rarely & sometimes/rarely & sometimes/rarely & agree & agree & agree/neutral \\
\hline Mean (SD) & $3.3(1.6)$ & $3.5(1.5)$ & $3.6(1.4)$ & $2.0(1.2)$ & $2.1(1.0)$ & $2.3(1.1)$ \\
\hline \multicolumn{7}{|c|}{ Netherlands $(n=77)$} \\
\hline Response rate & $55 \%$ & $57 \%$ & $38 \%$ & $74 \%$ & $76 \%$ & $64 \%$ \\
\hline Mean response & sometimes & sometimes & sometimes & agree & agree & agree \\
\hline Mean (SD) & $3.0(1.4)$ & $2.9(1.4)$ & $3.2(1.4)$ & $2.1(1.0)$ & $1.9(0.9)$ & $2.0(0.9)$ \\
\hline \multicolumn{7}{|c|}{ Vancouver $(n=119)$} \\
\hline Response rate & $78 \%$ & $72 \%$ & $61 \%$ & $78 \%$ & $82 \%$ & $74 \%$ \\
\hline Mean response & often/sometimes & often/sometimes & sometimes & agree & agree & agree \\
\hline Mean (SD) & $2.3(1.4)$ & $2.4(1.4)$ & $3.1(1.5)$ & $1.8(1.2)$ & $1.8(1.1)$ & $2.1(1.3)$ \\
\hline
\end{tabular}

Note. For practice items: 1 = always, 2 = often, 3 = sometimes, 4 = rarely, 5 = never. For opinion items: $1=$ strongly agree (agree + ), 2 = agree, 3 = neutral, 4 = disagree, 5 = strongly disagree $($ disagree + ).

*This is the percentage of respondents from a site who provided ratings of 1-5; "do not know/not applicable” responses were not included. 
Table 5

Responses to whether children who are obligatory bilinguals* are and should be exposed to English/Dutch only, by site

\begin{tabular}{|c|c|c|c|c|c|c|}
\hline & \multicolumn{3}{|c|}{ ARE exposed to English (Dutch) only? } & \multicolumn{3}{|c|}{ SHOULD be exposed to English (Dutch) only? } \\
\hline & TD & Mild & Severe & TD & Mild & Severe \\
\hline \multicolumn{7}{|c|}{ Albuquerque $(n=36)$} \\
\hline Response rate** & $78 \%$ & $76 \%$ & $71 \%$ & $82 \%$ & $83 \%$ & $81 \%$ \\
\hline Mean response & sometimes & often/sometimes & often/sometimes & $\begin{array}{c}\text { disagree/ } \\
\text { disagree+ }\end{array}$ & $\begin{array}{c}\text { disagree/ } \\
\text { disagree+ }\end{array}$ & $\begin{array}{c}\text { disagree/ } \\
\text { disagree+ }\end{array}$ \\
\hline Mean (SD) & $2.8(1.1)$ & $2.7(1.2)$ & $2.6(1.4)$ & $4.3(1.0)$ & $4.4(0.8)$ & $4.3(0.8)$ \\
\hline \multicolumn{7}{|c|}{ Halifax $(n=61)$} \\
\hline Response rate & $75 \%$ & $74 \%$ & $71 \%$ & $80 \%$ & $78 \%$ & $75 \%$ \\
\hline Mean response & often & often & often & neutral/disagree & neutral/disagree & neutral/disagree \\
\hline Mean (SD) & $2.0(1.1)$ & $2.0(1.2)$ & $2.1(1.4)$ & $3.6(1.2)$ & $3.6(1.2)$ & $3.6(1.3)$ \\
\hline \multicolumn{7}{|c|}{ Manchester $(n=45)$} \\
\hline Response rate & $80 \%$ & $76 \%$ & $63 \%$ & $83 \%$ & $82 \%$ & $74 \%$ \\
\hline Mean response & often/sometimes & often/sometimes & often/sometimes & neutral/disagree & neutral/disagree & disagree \\
\hline Mean (SD) & $2.3(1.4)$ & $2.4(1.4)$ & $2.5(1.4)$ & $3.6(1.1)$ & $3.6(1.1)$ & $3.8(1.0)$ \\
\hline
\end{tabular}

Table Continues 


\begin{tabular}{|c|c|c|c|c|c|c|}
\hline \multicolumn{7}{|c|}{ Montreal $(n=23)$} \\
\hline Response rate & $52 \%$ & $71 \%$ & $68 \%$ & $63 \%$ & $76 \%$ & $74 \%$ \\
\hline Mean response & rarely/never & rarely & sometimes/rarely & $\begin{array}{c}\text { disagree/ } \\
\text { disagree+ }\end{array}$ & disagree & neutral/disagree \\
\hline Mean (SD) & $4.3(1.2)$ & $3.8(1.4)$ & $3.6(1.5)$ & $4.4(1.1)$ & $3.8(1.4)$ & $3.5(1.6)$ \\
\hline \multicolumn{7}{|c|}{ Netherlands $(n=77)$} \\
\hline Response rate & $58 \%$ & $62 \%$ & $44 \%$ & $59 \%$ & $63 \%$ & $51 \%$ \\
\hline Mean response & always/often & always/often & often & neutral & neutral & neutral \\
\hline Mean (SD) & $1.7(1.0)$ & $1.7(0.9)$ & $1.8(1.1)$ & $2.9(1.2)$ & $3.0(1.2)$ & $3.1(1.1)$ \\
\hline \multicolumn{7}{|c|}{ Vancouver $(n=119)$} \\
\hline Response rate & $84 \%$ & $85 \%$ & $78 \%$ & $84 \%$ & $85 \%$ & $81 \%$ \\
\hline Mean response & often/sometimes & often & often & neutral/disagree & neutral/disagree & neutral/disagree \\
\hline Mean & $2.3(1.2)$ & $2.2(1.1)$ & $2.1(1.2)$ & $3.7(1.3)$ & $3.5(1.3)$ & $3.4(1.3)$ \\
\hline \multicolumn{7}{|c|}{ Note. For practice: 1 = always, 2 = often, 3 = sometimes, 4 = rarely, $5=$ never; For opinion, $1=$ strongly agree $($ agree + ), $2=$ agree, $3=$} \\
\hline \multicolumn{7}{|c|}{ *Obligatory bilinguals are English/Dutch language learners and simultaneous bilinguals combined. } \\
\hline \multicolumn{7}{|c|}{ **This is the percentage of respondents from a site who provided ratings of 1-5; “do not know/not applicable” responses were not } \\
\hline
\end{tabular}


Table 6

Responses to whether children who are obligatory bilinguals* are and should be assessed and treated in English/Dutch only, by site**

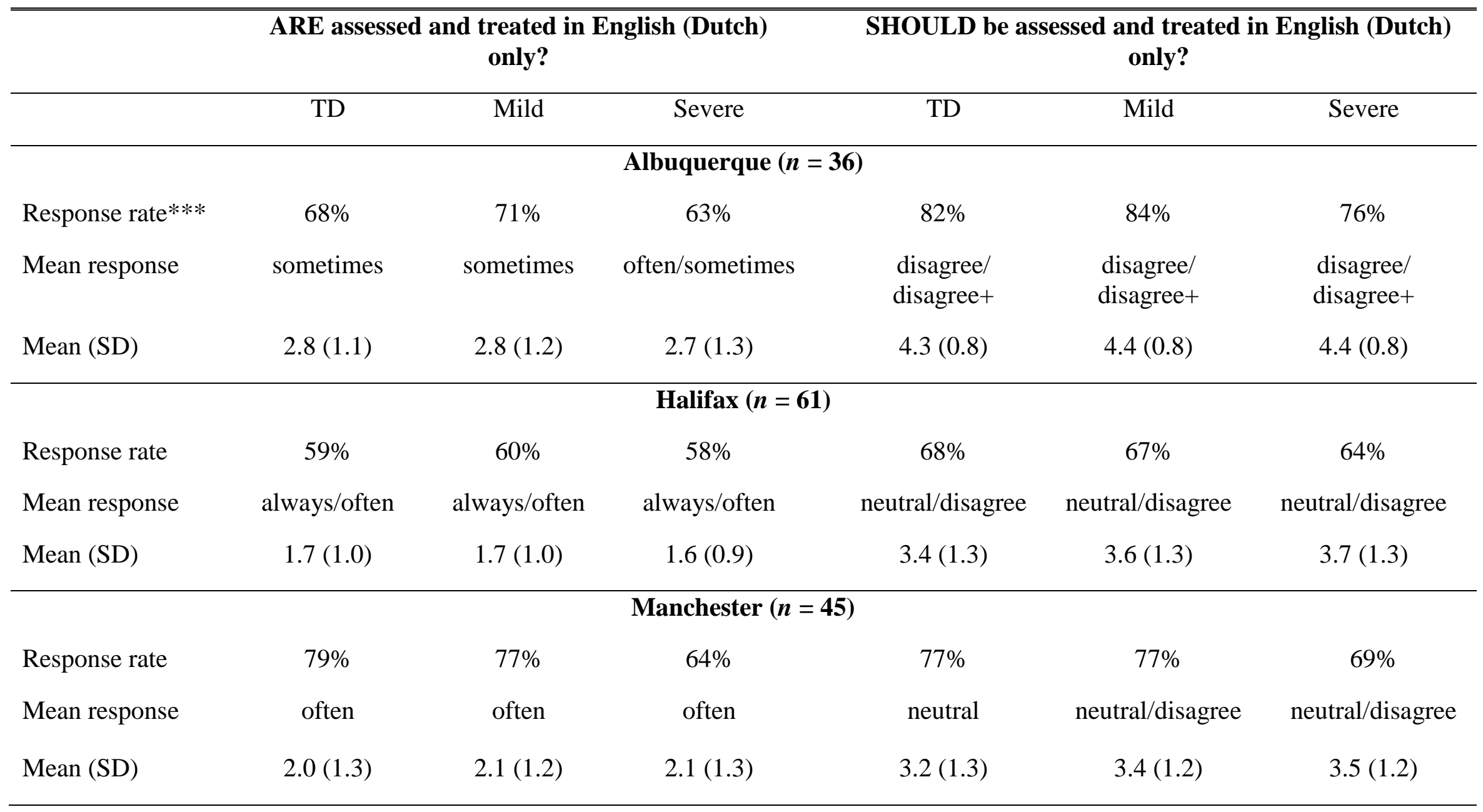

Table Continues 
Practices and Opinions about Bilingual Services 41

\begin{tabular}{|c|c|c|c|c|c|c|}
\hline \multicolumn{7}{|c|}{ Montreal $(n=23)$} \\
\hline Response rate & $50 \%$ & $61 \%$ & $60 \%$ & $52 \%$ & $64 \%$ & $65 \%$ \\
\hline Mean response & rarely & sometimes/rarely & sometimes/rarely & disagree & neutral/disagree & neutral/disagree \\
\hline Mean (SD) & $4.0(1.0)$ & $3.5(1.1)$ & $3.3(1.2)$ & $4.0(1.4)$ & $3.6(1.4)$ & $3.3(1.6)$ \\
\hline \multicolumn{7}{|c|}{ Vancouver $(n=119)$} \\
\hline Response rate & $76 \%$ & $79 \%$ & $72 \%$ & $77 \%$ & $80 \%$ & $74 \%$ \\
\hline Mean response & often & often & often & neutral/disagree & neutral/disagree & neutral/disagree \\
\hline Mean & $2.1(1.2)$ & $2.0(1.1)$ & $1.9(1.1)$ & $3.4(1.4)$ & $3.5(1.3)$ & $3.5(1.2)$ \\
\hline
\end{tabular}

Note. For practice: 1 = always, 2 = often, 3 = sometimes, 4 = rarely, 5 = never; For opinion, 1 = strongly agree (agree+), $2=$ agree, $3=$

neutral, 4 = disagree, 5 = strongly disagree $($ disagree + ).

*Obligatory bilinguals are English language learners and simultaneous bilinguals combined.

**Data for the Netherlands were not included in this analysis.

***This is the percentage of respondents from a site who provided ratings of 1-5; “do not know/not applicable” responses were not included 
Table 7

Responses to whether children who are optional second language learners do and should participate in language classes, by site

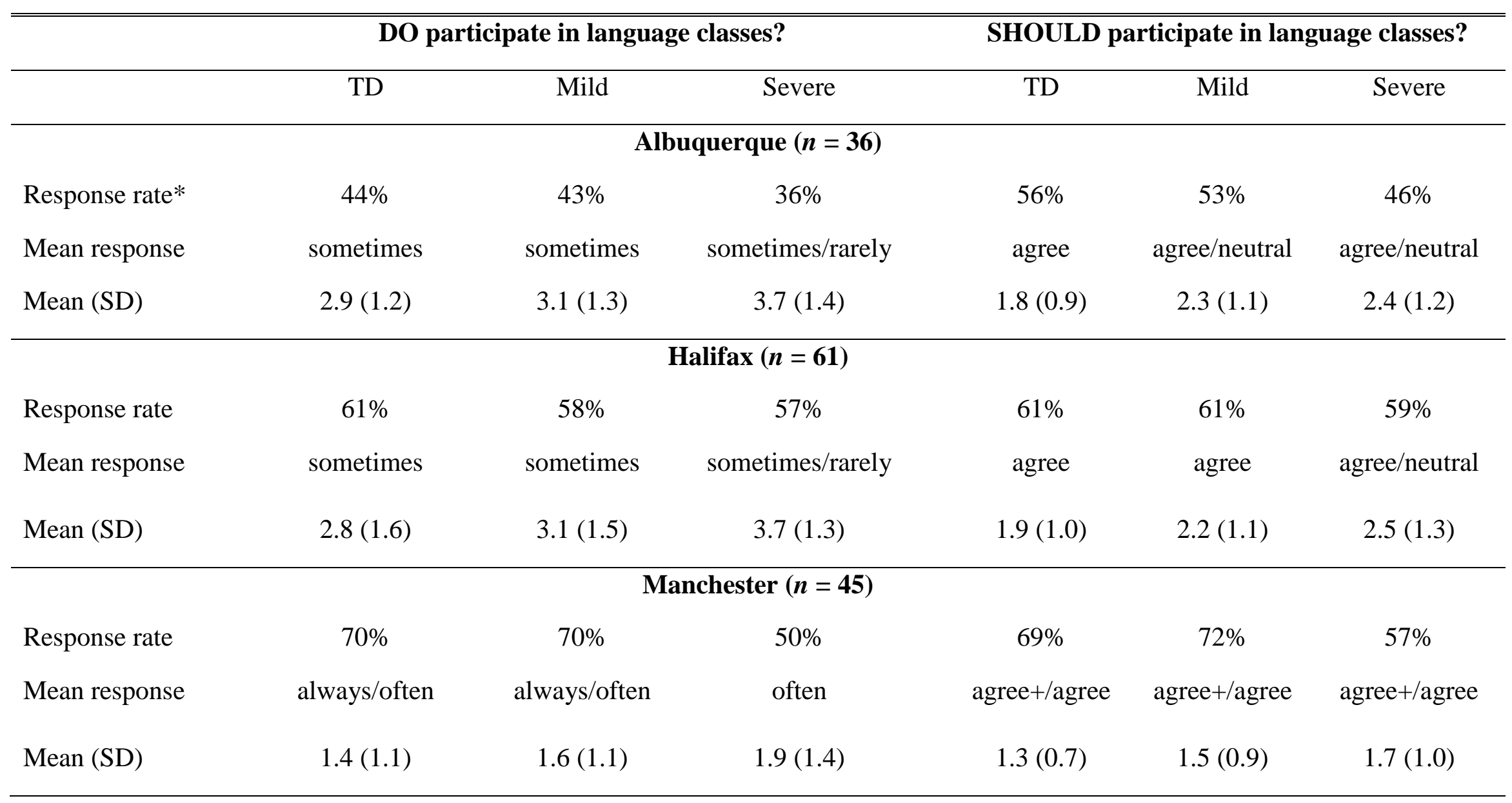

Table Continues 


\begin{tabular}{|c|c|c|c|c|c|c|}
\hline \multicolumn{7}{|c|}{ Montreal $(n=23)$} \\
\hline Response rate & $30 \%$ & $52 \%$ & $43 \%$ & $30 \%$ & $48 \%$ & $44 \%$ \\
\hline Mean response & often & often & often/sometimes & agree & agree/neutral & neutral \\
\hline Mean (SD) & $2.1(1.6)$ & $2.2(1.2)$ & $2.6(1.5)$ & $1.9(1.5)$ & $2.3(1.5)$ & $3.0(1.7)$ \\
\hline \multicolumn{7}{|c|}{ Netherlands $(n=77)$} \\
\hline Response rate & $26 \%$ & $32 \%$ & $21 \%$ & $32 \%$ & $38 \%$ & $26 \%$ \\
\hline Mean response & often/sometimes & often/sometimes & sometimes/rarely & agree/neutral & agree/neutral & neutral \\
\hline Mean (SD) & $2.7(1.7)$ & $2.7(1.6)$ & $3.5(1.5)$ & $2.4(1.4)$ & $2.5(1.3)$ & $3.1(1.2)$ \\
\hline \multicolumn{7}{|c|}{ Vancouver $(n=119)$} \\
\hline Response rate & $50 \%$ & $52 \%$ & $45 \%$ & $51 \%$ & $52 \%$ & $48 \%$ \\
\hline Mean response & often & often/sometimes & rarely & agree+/agree & agree/neutral & neutral \\
\hline Mean & $1.9(1.3)$ & $2.7(1.4)$ & $3.9(1.3)$ & $1.7(1.1)$ & $2.3(1.2)$ & $3.2(1.3)$ \\
\hline
\end{tabular}




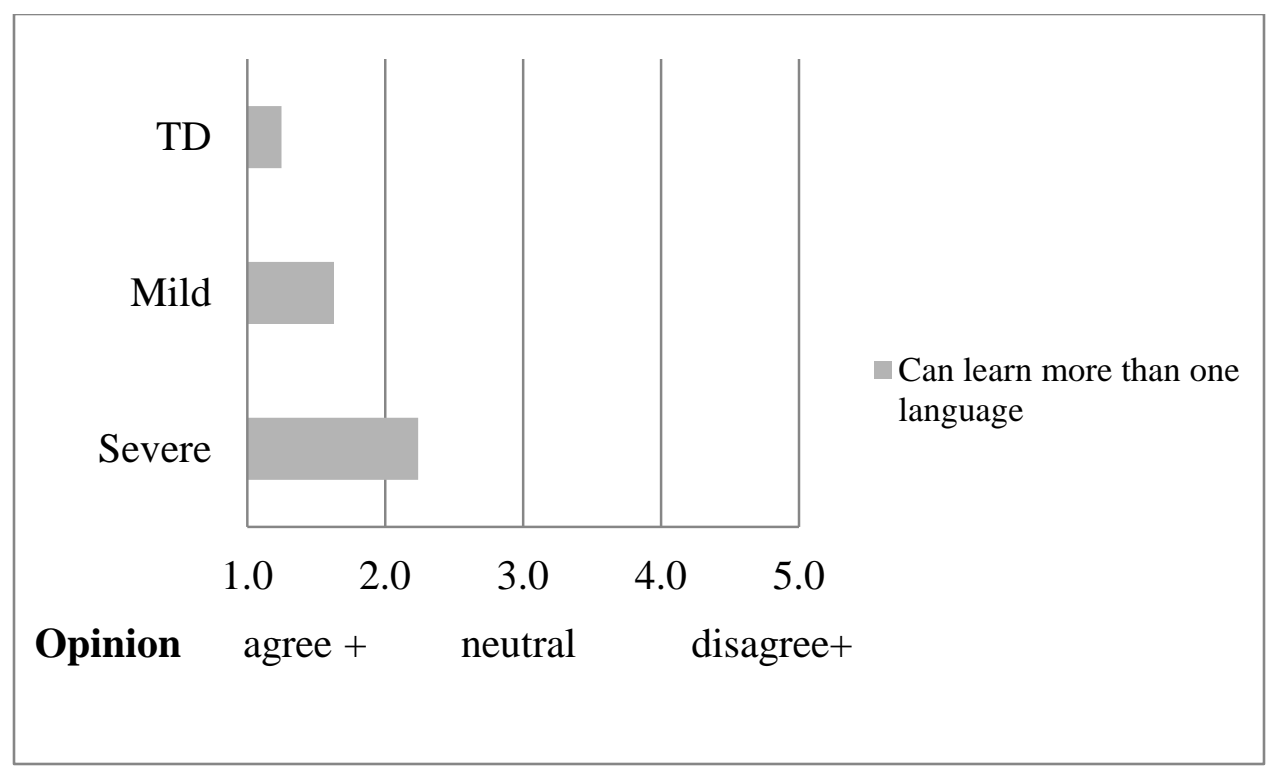

Figure 1. Can children learn more than one language? 


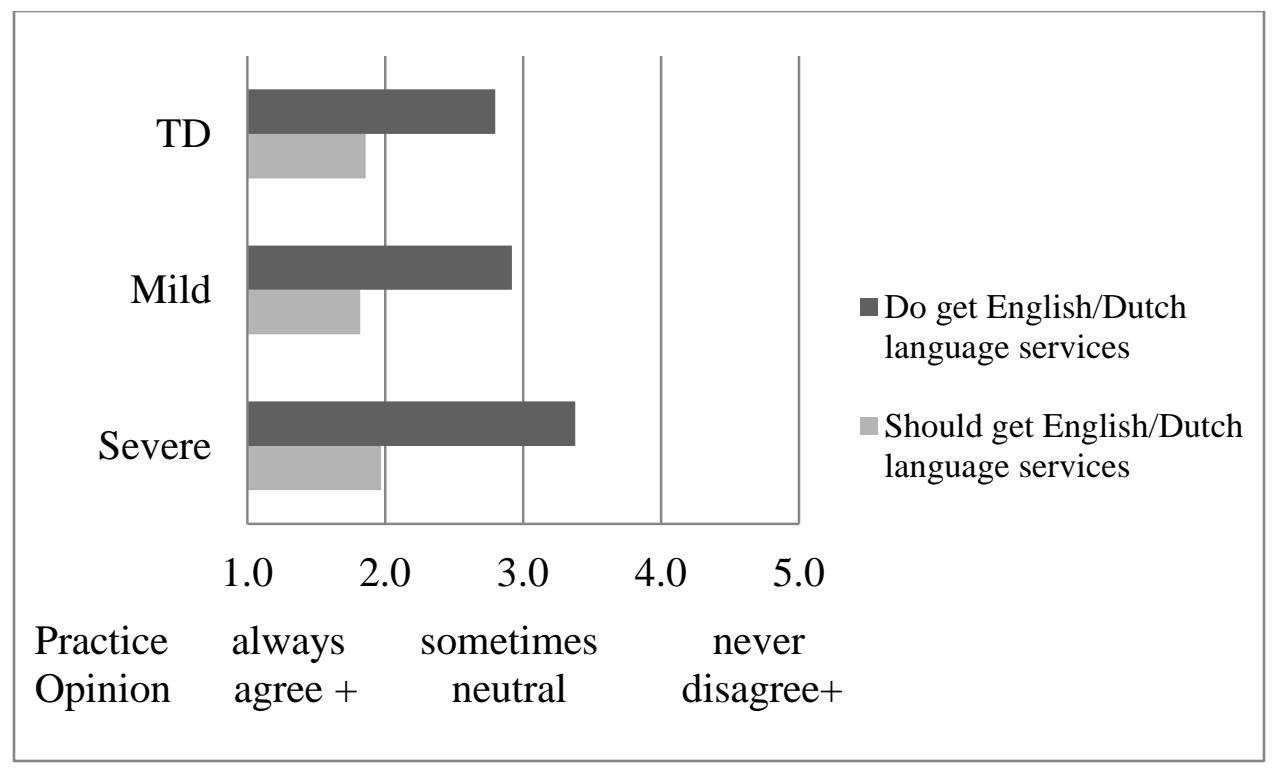

Figure 2. Do/should English/Dutch language learners (currently) receive language services in your work environment? 


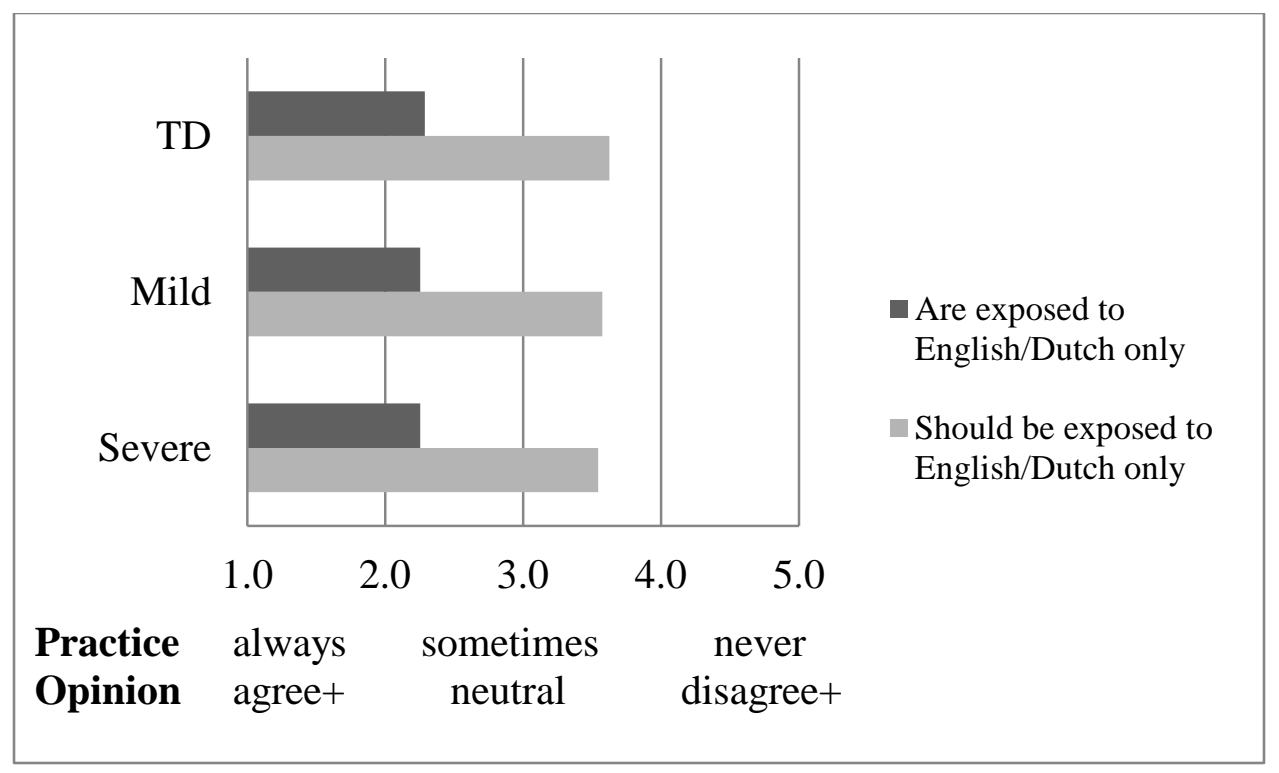

Figure 3. Obligatory bilinguals are/should be exposed to English/Dutch only in your work environment 


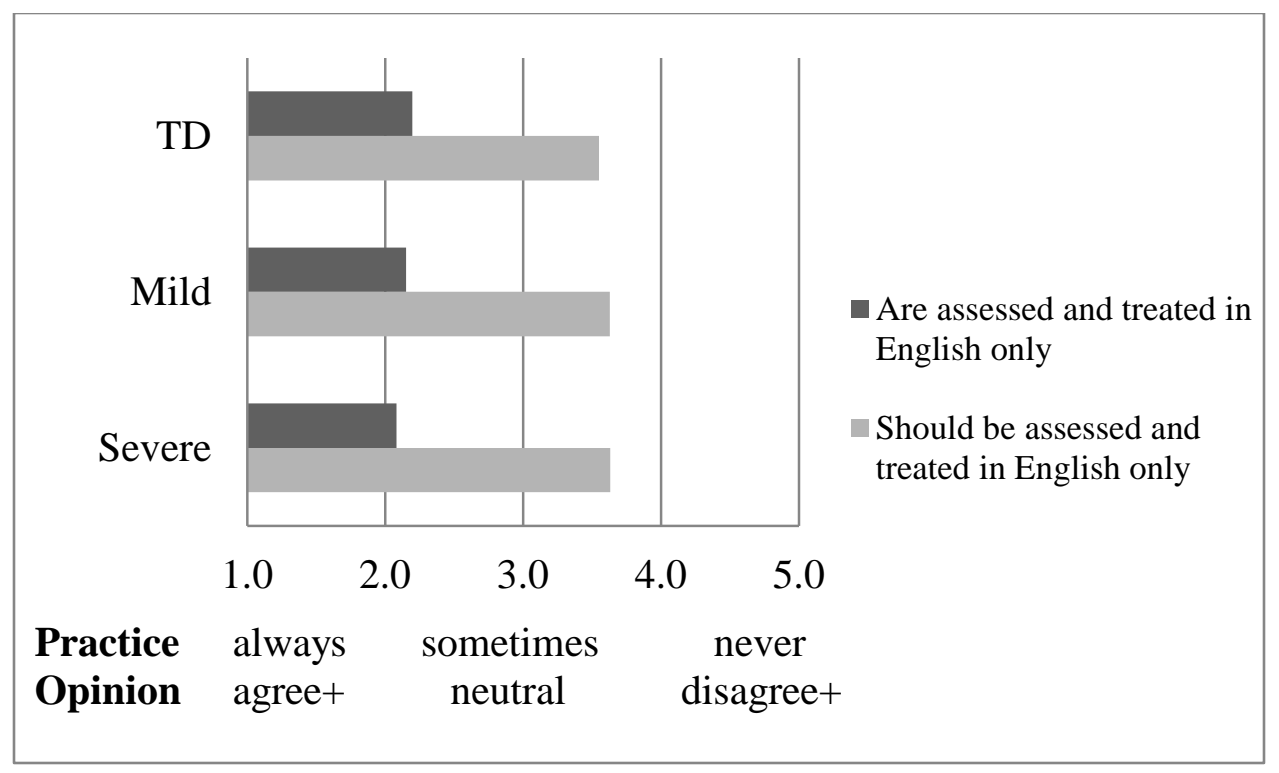

Figure 4. Obligatory bilinguals are/should be assessed and treated in English only in your work environment 


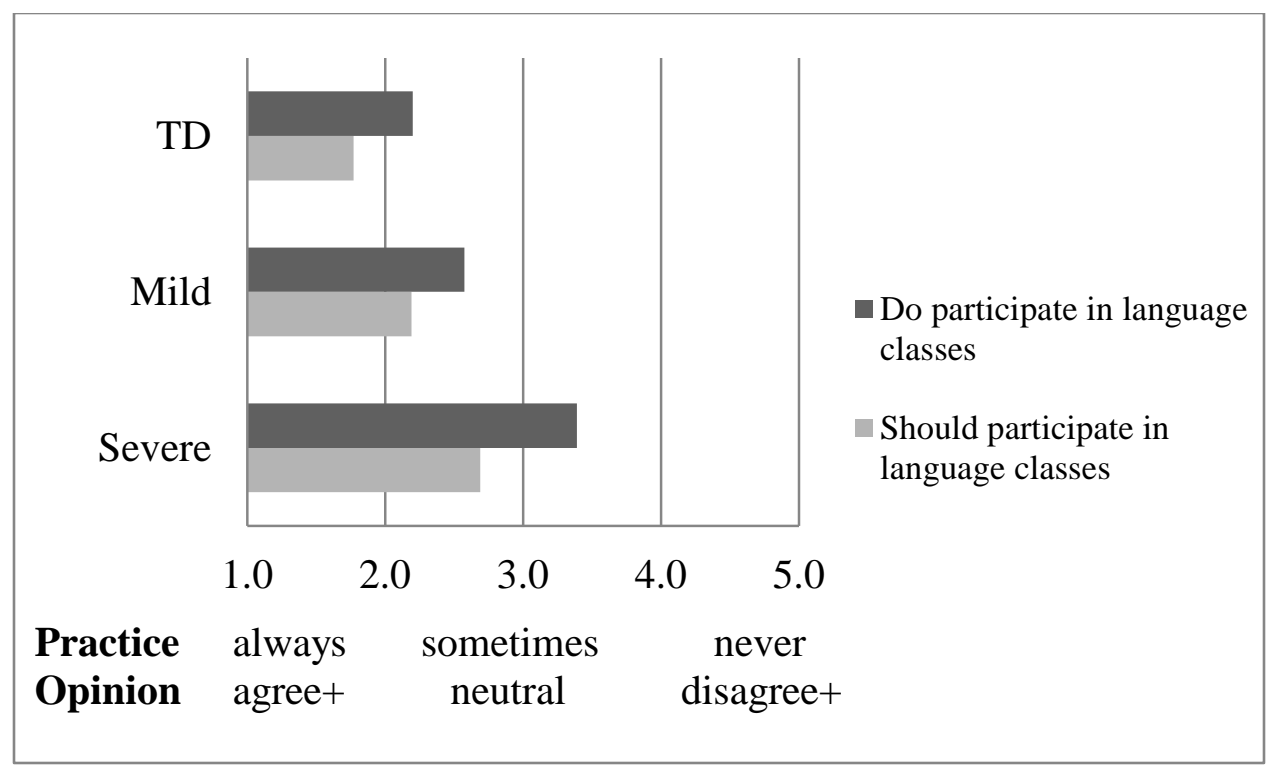

Figure 5. Do/should optional second language learners in your work environment participate in language classes? 


\section{Appendix A: Survey Items Included in this Study \\ Practice Items}

1. [Clinical group] who are English language learners (ELLs)* currently receive ELL services in your work environment.

2. [Clinical group] who are ELLS are currently exposed to English only in your work environment.

3. [Clinical group] who are simultaneous bilinguals are currently exposed to English only in your work environment.

4. [Clinical group] who are ELLS are assessed and treated in English only in your work environment.

5. [Clinical group] who are simultaneous bilinguals are assessed and treated in English only in your work environment.

6. [Clinical group] who are optional language learners currently participate in language classes in your work environment.

\section{Opinion Items}

1. In your opinion, [clinical group] have the capacity to learn more than one language.

2. In your opinion, [clinical group] who are ELLs should receive ELL services in your work environment.

3. In your opinion, [clinical group] who are ELLs should be exposed to English only in your work environment.

4. In your opinion, [clinical group] who are simultaneous bilinguals should be exposed to English only in your work environment.

5. In your opinion, [clinical group] who are ELLs should be assessed and treated in English only in your work environment. 
6. In your opinion, [clinical group] who are simultaneous bilinguals should be assessed and treated in English only in your work environment.

7. In your opinion, [clinical group] who are optional language learners should participate in language classes in your work environment.

*In the Netherlands, these references were to Dutch language learner or Dutch in all relevant places. 


\section{Appendix B: Response Formats for Clinical Groups*}

\section{Practice Items}

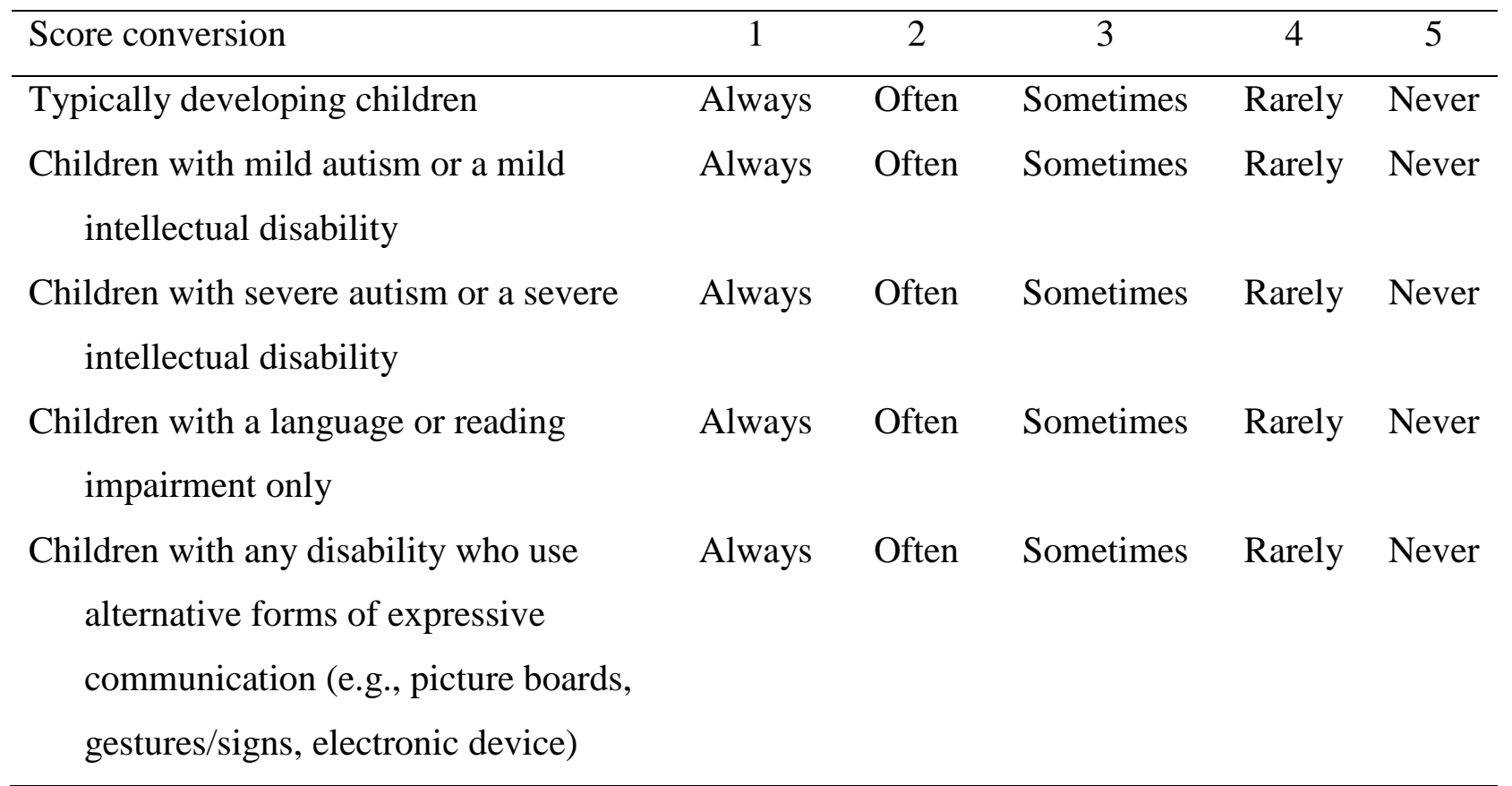

\section{Opinion Items}

\begin{tabular}{|c|c|c|c|c|c|}
\hline Score conversion & 1 & 2 & 3 & 4 & 5 \\
\hline Typically developing children & $\begin{array}{c}\text { Strongly } \\
\text { Agree }\end{array}$ & Agree & Neutral & Disagree & $\begin{array}{l}\text { Strongly } \\
\text { Disagree }\end{array}$ \\
\hline $\begin{array}{l}\text { Children with mild autism or a mild } \\
\text { intellectual disability }\end{array}$ & $\begin{array}{c}\text { Strongly } \\
\text { Agree }\end{array}$ & Agree & Neutral & Disagree & $\begin{array}{l}\text { Strongly } \\
\text { Disagree }\end{array}$ \\
\hline $\begin{array}{l}\text { Children with severe autism or a } \\
\text { severe intellectual disability }\end{array}$ & $\begin{array}{c}\text { Strongly } \\
\text { Agree }\end{array}$ & Agree & Neutral & Disagree & $\begin{array}{l}\text { Strongly } \\
\text { Disagree }\end{array}$ \\
\hline $\begin{array}{l}\text { Children with a language or reading } \\
\text { impairment only }\end{array}$ & $\begin{array}{c}\text { Strongly } \\
\text { Agree }\end{array}$ & Agree & Neutral & Disagree & $\begin{array}{l}\text { Strongly } \\
\text { Disagree }\end{array}$ \\
\hline $\begin{array}{l}\text { Children with any disability who use } \\
\text { alternative forms of expressive } \\
\text { communication (e.g., picture boards, } \\
\text { gestures/signs, electronic devices) }\end{array}$ & $\begin{array}{c}\text { Strongly } \\
\text { Agree }\end{array}$ & Agree & Neutral & Disagree & $\begin{array}{l}\text { Strongly } \\
\text { Disagree }\end{array}$ \\
\hline
\end{tabular}

Note. "do not know" and "not applicable" options were also included but were not used in the analyses for this report 